\title{
FREE VIBRATION ANALYSIS OF LAMINATED STIFFENED CYLINDRICAL PANELS USING FINITE ELEMENT METHOD
}

\author{
Trinh Anh Tuan ${ }^{1}$, Tran Huu Quoc ${ }^{2}$, Tran Minh $\mathbf{T u}^{2, *}$ \\ ${ }^{1}$ HSE Training and Design Consultancy Company Limited, \\ 36B, 51 Lane, Doc Ngu Str., Ba Dinh Dist., Hanoi \\ ${ }^{2}$ University of Civil Engineering, 55 Giai Phong Road, Hai Ba Trung District, Ha Noi \\ "Email:tpnt2002@yahoo.com
}

Received: 20 April 2016; Accepted for publication: 20 September 2016

\begin{abstract}
A study on the free vibration analysis of stiffened laminated composite cylindrical shell is described in this paper. The eight-noded isoparametric degenerated shell element is developed to model both shell panel and stiffeners by using the degenerated solid concept based on ReissnerMindlin assumptions which taking into account the shear deformation and rotatory effect. Numerical results are presented and comparison is made with the published results from the literature and the good agreement is found. Parametric studies considering different geometrical variables of shell and stiffeners have also been carried out.
\end{abstract}

Keywords: laminated composite shells; stiffened shells; vibration analysis; finite elements; degenerated shell element; static analysis.

\section{INTRODUCTION}

Laminated composite shells and particularly cylindrical panels are increasingly used in many engineering applications such as aerospace, mechanical, civil and marine engineering structures. The cylindrical panels are often stiffened by stiffener and ring to enhance the specific strength/stiffness to weight ratio of the structure. The vibration characteristics of stiffened cylindrical panels are of considerable importance to mechanical and structural engineers.

Vibration of cylindrical shells has been extensively studied by many researchers. The vibration analysis of shell is presented in work done by Leissa [1], and Soedel [2]. Quatu [3] studied vibration of laminated composite shells and plates and reviewed in his textbook. The investigation on stiffened shell vibration is still meager. There are two classes of analysis of stiffened plate/shells.

First, the stiffened structures can be modeled as equivalent homogenous isotropic or orthotropic plate/shell. This is done by smearing the properties and effects of the stiffeners or the corrugations over the surface of the plate/shell. This is very efficient but it could not be used for stress-strain analysis. In addition, there is a severe strictness in the applicability of the model to a generalized problem which is due to the simplicity inherent in the approximation. The 
orthotropic model can be applied when the stiffeners are identical, light, closely spaced and having equal spacing and the orientation of stiffeners is orthogonal. Using smearing technique to solve technical problems, Szilard [4] has reported in his work. Luan Y. et al. [5, 6] also used this technique to analyze vibration characteristic of simply supported doubly curved cross-stiffened shells, and then improved it for modeling vibrations of cross-stiffened, thin rectangular plates.

Secondly, the plate/shell and the stiffeners are modeled as the discrete elements. This approach describes better structural behavior and it has been adopted for the analysis of stiffened and corrugated plate/shells. In this case, the numerical methods are applied to solve the governing differential equations.

Among the known numerical methods, the finite element method is certainly the most favourable. Using the finite element model where stiffeners are modeled by beam finite elements, Mustafa and Ali [7] and Bardell and Mead [8] have presented the vibration analysis of orthogonally stiffened cylindrical shells. Goswami and Mukhopadhyay $[9,10]$ studied deflection and free vibration of laminated stiffened composite panels by using the nine-noded Lagrangian element and heterosis element to model the shell and the stiffener. Employing eight-noded isoparametric quadratic element for the shell, three-noded curved beam element for the stiffener Prusty and Satsangi $[11,12,13]$ investigated static, failure analysis and vibration characteristic of laminated composite stiffened panels based on first order shell theory. Jiang and Olson [14] developed a super finite element with $\mathrm{C}^{0}$ shell element and curved beam element for the free vibration analysis of cylindrical shells. Using the eight-/nine-node doubly curved isoparametric thin shallow shell element with the three-node curved isoparametric beam element, Nayak and Bandyopadhyay [15] analyzed free vibration behavior of doubly curved stiffened shallow shells.

Using triangular shallow shell finite element and beam element for stiffener, Sinha and Mukhopadhyay carried out the free vibration analysis of eccentric stiffened plates/ shallow shells. Triangular flat shell element and 3D beam element for stiffener has already been used by Samanta and Mukhopadhyay [16] to determine natural frequencies and mode shapes of the different stiffened structures. In order to model a shell panel without any significant approximation related to the representation of arbitrary shell geometry, structural deformation and other associated aspects, the isoparametric 3D degenerated shell element is used.

In the formulation of degenerated shell element has been the first time proposed by Ahmad [17]. This element is derived by degenerating a 3D solid element into a shell surface element, by deleting the intermediate nodes in the thickness direction and then by projecting the nodes on each surface to the mid-surface. This approach has the advantage of being independent of any particular shell theory. This approach can be used to formulate a general shell element for geometric and material nonlinear analysis. The assumptions for degenerated shell are similar to the Reissner-Mindlin assumptions.

A three-dimensional (3-D) degenerated shell element and a 3-D degenerated curved beam element are employed to model plates/shells and stiffeners is applied by Liao and Chen [18] to investigate the dynamic stability of laminated composite stiffened or non-stiffened plates and shells. Patel et al. [19] used the eight-noded isoparametric degenerated shell element and a compatible three-noded curved beam element are used to model the shell/panels and the stiffeners to analyze buckling and dynamic instability of stiffened shell panels.

In the present study, the vibration analysis is carried out for laminated stiffened circular cylindrical panels. The first order shell theory is used, and the eight-noded degenerated 3D shell element is employed to model the shell panels and the stiffeners. 


\section{FINITE ELEMENT FORMULATION}

\subsection{Shell element}

Let consider a degenerated shell element, obtained by degenerating 3D solid element. The degenerated shell element as shown in Figure 1 has eight nodes, for which the analysis is carried out. Let $(\xi, \eta)$ are the natural coordinates in the mid-surface. And $\varsigma$ is the natural coordinate along thickness direction. The shape functions of a two dimensional eight node isoparametric element are:

$$
\begin{array}{ll}
N_{1}=-\frac{1}{4}(1-\xi)(1-\eta)(1+\xi+\eta) & N_{5}=\frac{1}{2}\left(1-\xi^{2}\right)(1-\eta) \\
N_{2}=-\frac{1}{4}(1+\xi)(1-\eta)(1-\xi+\eta) & N_{6}=\frac{1}{2}(1+\xi)\left(1-\eta^{2}\right) \\
N_{3}=-\frac{1}{4}(1+\xi)(1+\eta)(1-\xi-\eta) & N_{7}=\frac{1}{2}\left(1-\xi^{2}\right)(1+\eta) \\
N_{4}=-\frac{1}{4}(1-\xi)(1+\eta)(1+\xi-\eta) & N_{8}=\frac{1}{2}(1-\xi)\left(1-\eta^{2}\right)
\end{array}
$$

\subsection{Displacement field}

The position of any point inside the shell element can be written in terms of nodal coordinates as

$$
\left\{\begin{array}{l}
x \\
y \\
z
\end{array}\right\}=\sum_{i=1}^{8} N_{i}(\xi, \eta)\left\{\frac{1+\varsigma}{2}\left\{\begin{array}{c}
x_{i} \\
y_{i} \\
z_{i}
\end{array}\right\}_{\text {top }}+\frac{1-\varsigma}{2}\left\{\begin{array}{c}
x_{i} \\
y_{i} \\
z_{i}
\end{array}\right\}_{\text {bottom }}\right\}
$$

Since, $\varsigma$ is assumed to be normal to the mid surface, the above expression can be rewritten in terms of a vector connecting the upper and lower points of shell as

$$
\left\{\begin{array}{l}
x \\
y \\
z
\end{array}\right\}=\sum_{i=1}^{8} N_{i}(\xi, \eta)\left\{\frac{1}{2}\left\{\left\{\begin{array}{c}
x_{i} \\
y_{i} \\
z_{i}
\end{array}\right\}_{\text {top }}+\left\{\begin{array}{c}
x_{i} \\
y_{i} \\
z_{i}
\end{array}\right\}_{\text {bottom }}\right\}+\frac{\varsigma}{2}\left\{\left\{\begin{array}{c}
x_{i} \\
y_{i} \\
z_{i}
\end{array}\right\}_{\text {top }}-\left\{\begin{array}{c}
x_{i} \\
y_{i} \\
z_{i}
\end{array}\right\}_{\text {bottom }}\right\}\right\}
$$

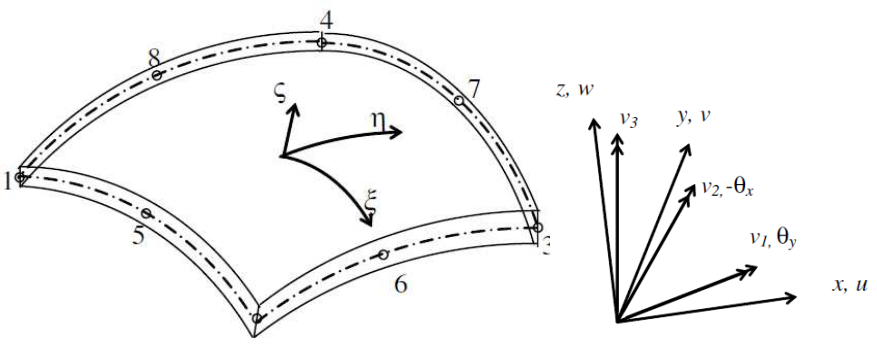

2

Figure 1. Eight-noded quadrilateral degenerated 3D shell element,

Cited in Ahmad [17].

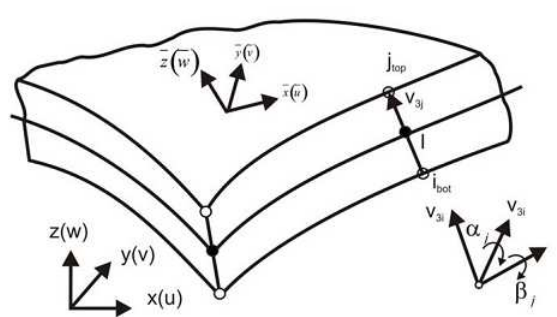

Figure 2. Local and global coordinates, Cited in Ahmad [17]. 


$$
\text { or, }\left\{\begin{array}{l}
x \\
y \\
z
\end{array}\right\}=\sum_{i=1}^{8} N_{i}(\xi, \eta)\left\{\left\{\begin{array}{l}
x_{i} \\
y_{i} \\
z_{i}
\end{array}\right\}+\frac{\varsigma}{2} V_{3 i}\right\}
$$

where,

$$
\left\{\begin{array}{l}
x_{i} \\
y_{i} \\
z_{i}
\end{array}\right\}=\frac{1}{2}\left\{\left\{\begin{array}{l}
x_{i} \\
y_{i} \\
z_{i}
\end{array}\right\}_{\text {top }}+\left\{\begin{array}{l}
x_{i} \\
y_{i} \\
z_{i}
\end{array}\right\}_{\text {bottom }}\right\} \text { and } V_{3 i}=\left\{\begin{array}{c}
x_{i} \\
y_{i} \\
z_{i}
\end{array}\right\}_{\text {top }}-\left\{\begin{array}{c}
x_{i} \\
y_{i} \\
z_{i}
\end{array}\right\}_{\text {bottom }}
$$

For small thickness, the nodal vector along the thickness direction $\boldsymbol{V}_{3 \mathrm{i}}$ can be represented as a unit vector $h_{\mathrm{i}} \boldsymbol{v}_{3 \mathrm{i}}$ :

$$
\left\{\begin{array}{l}
x \\
y \\
z
\end{array}\right\}=\sum_{i=1}^{8} N_{i}(\xi, \eta)\left\{\left\{\begin{array}{l}
x_{i} \\
y_{i} \\
z_{i}
\end{array}\right\}+\frac{\varsigma}{2} h_{i} \nu_{3 i}\right\}
$$

where, $h_{\mathrm{i}}$ is the thickness of shell at $i$-th node. In a similar way, the displacement at any point of the shell element can be expressed in terms of three displacements $\left(u_{i}, v_{i}, w_{i}\right)$ and three rotation components $\left(\theta_{x i}, \theta_{y i}\right)$ at the mid-surface nodes as follows:

$$
\left\{\begin{array}{l}
u \\
v \\
w
\end{array}\right\}=\sum_{i=1}^{8} N_{i}(\xi, \eta)\left\{\left\{\begin{array}{c}
u_{i} \\
v_{i} \\
w_{i}
\end{array}\right\}-\frac{\varsigma}{2} h_{i}\left[\begin{array}{cc}
l_{1 i} & l_{2 i} \\
m_{1 i} & m_{2 i} \\
n_{1 i} & n_{2 i}
\end{array}\right]\left[\begin{array}{c}
\theta_{x i} \\
\theta_{y i}
\end{array}\right]\right\}=\left[N_{D}\right]\{\delta\}
$$

where, $\left(\theta_{x i}, \theta_{y i}\right)$ are the rotations of two unit vectors $v_{1 \mathrm{i}} \& v_{2 \mathrm{i}}$ about two orthogonal directions normal to nodal vector $\boldsymbol{V}_{3 \mathrm{i}}$. The values of unit vectors $v_{1 \mathrm{i}}$ and $v_{2 \mathrm{i}}$ can be determined in the following form:

$$
\left\{\nu_{1 i}\right\}=\left[\begin{array}{lll}
l_{1 i} & m_{1 i} & n_{1 i}
\end{array}\right]^{T},\left\{\nu_{2 i}\right\}=\left[\begin{array}{lll}
l_{2 i} & m_{2 i} & n_{2 i}
\end{array}\right]^{T} .
$$

\subsection{Strain field}

The strain components with respect to the global coordinates can be expressed from the displacement as

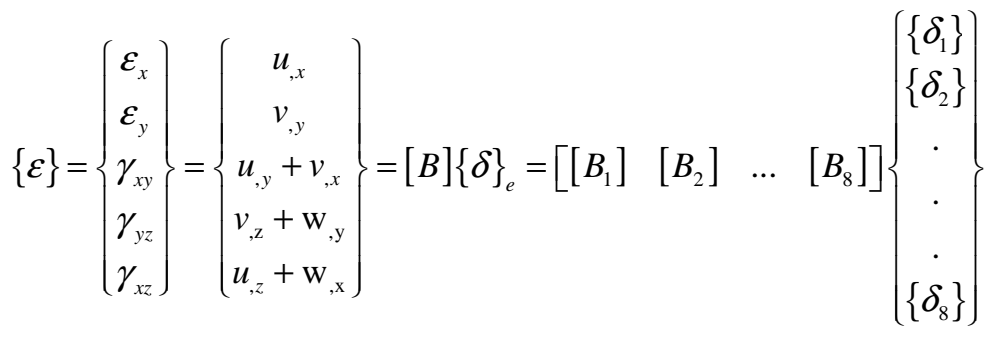

in which, $\{\delta\}$ is the nodal displacement vector of an element and it is: 


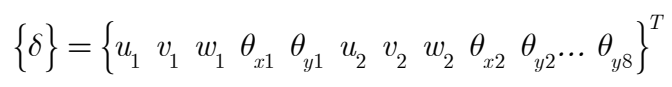

And the matrix $\left[B_{i}\right]$ are called the strain displacement matrix

$$
\left[B_{i}\right]=\left[\begin{array}{ccccc}
a_{i} & 0 & 0 & d_{i} l_{1 i} & d_{i} l_{2 i} \\
0 & b_{i} & 0 & e_{i} m_{1 i} & e_{i} m_{2 i} \\
0 & 0 & c_{i} & g_{i} n_{1 i} & g_{i} n_{2 i} \\
b_{i} & a_{i} & 0 & e_{i} l_{1 i}+d_{i} m_{1 i} & e_{i} l_{2 i}+d_{i} m_{2 i} \\
0 & c_{i} & b_{i} & g_{i} m_{1 i}+e_{i} n_{1 i} & g_{i} m_{2 i}+e_{i} n_{2 i} \\
c_{i} & 0 & a_{i} & d_{i} n_{1 i}+g_{i} l_{1 i} & d_{i} n_{2 i}+g_{i} l_{2 i}
\end{array}\right]
$$

where $i=1 \div 8$ for a eight-noded shell element. The matrix coefficients are given by

$$
\left\{\begin{array}{l}
a_{i} \\
b_{i} \\
c_{i}
\end{array}\right\}=\left[\begin{array}{ll}
J_{11}^{*} & J_{12}^{*} \\
J_{21}^{*} & J_{22}^{*} \\
J_{31}^{*} & J_{32}^{*}
\end{array}\right]\left\{\begin{array}{l}
N_{i, \xi} \\
N_{i, \eta}
\end{array}\right\} \text { and }\left\{\begin{array}{l}
d_{i} \\
e_{i} \\
g_{i}
\end{array}\right\}=\frac{h_{i}}{2} \zeta\left\{\begin{array}{l}
a_{i} \\
b_{i} \\
c_{i}
\end{array}\right\}+\left\{\begin{array}{l}
J_{13}^{*} \\
J_{23}^{*} \\
J_{33}^{*}
\end{array}\right\} N_{i}
$$

where $[J]$ is the Jacobian and $\left[J^{*}\right]$ is the inverse Jacobian of transformation between global Cartesian coordinates and local isoparametric coordinates and given by

$$
[J]=\left[\begin{array}{ccc}
x_{, \xi} & y_{, \xi} & z_{, \xi} \\
x_{, \eta} & y_{, \eta} & z_{, \eta} \\
x_{, \zeta} & y_{, \zeta} & z_{, \zeta}
\end{array}\right] \quad(13) \quad[J]^{-1}=\left[J^{*}\right]=\left[\begin{array}{ccc}
\xi_{, x} & \eta_{, x} & \zeta_{, x} \\
\xi_{, y} & \eta_{, y} & \zeta_{y} \\
\xi_{, z} & \eta_{, z} & \zeta_{, z}
\end{array}\right]
$$

The local strains $\left\{\varepsilon^{\prime}\right\}$ are related to the global strain $\{\varepsilon\}$ as

$$
\left\{\varepsilon^{\prime}\right\}=\left\{\left\{\begin{array}{l}
\left\{\varepsilon_{p^{\prime}}\right\} \\
\left\{\gamma_{t^{\prime}}\right\}
\end{array}\right\}=\left\{\begin{array}{c}
\varepsilon_{x^{\prime}} \\
\varepsilon_{y^{\prime}} \\
\gamma_{x^{\prime} y^{\prime}} \\
\gamma_{y^{\prime} z^{\prime}} \\
\gamma_{x^{\prime} z^{\prime}}
\end{array}\right\}=\left\{\begin{array}{c}
\frac{\partial u}{\partial x^{\prime}} \\
\frac{\partial v}{\partial y^{\prime}} \\
\frac{\partial u}{\partial y^{\prime}}+\frac{\partial v}{\partial x^{\prime}} \\
\frac{\partial v}{\partial z^{\prime}}+\frac{\partial w}{\partial y^{\prime}} \\
\frac{\partial w}{\partial x^{\prime}}+\frac{\partial u}{\partial z^{\prime}}
\end{array}\right\}=\left[T_{\varepsilon}\right]\right\}\left\{\begin{array}{c}
\varepsilon_{x x} \\
\varepsilon_{y y} \\
\gamma_{x y} \\
\gamma_{y z} \\
\gamma_{x z}
\end{array}\right\}=\left[T_{\varepsilon}\right]\{\varepsilon\}
$$

where $\left[T_{\varepsilon}\right]$ the strain transformation matrix is given by

$$
\left[T_{\varepsilon}\right]=\left\{\begin{array}{cccccc}
l_{1}^{2} & m_{1}^{2} & n_{1}^{2} & l_{1} m_{1} & m_{1} n_{1} & n_{1} l_{1} \\
l_{2}^{2} & m_{2}^{2} & n_{2}^{2} & l_{2} m_{2} & m_{2} n_{2} & n_{2} l_{2} \\
2 l_{1} l_{2} & 2 m_{1} m_{2} & 2 n_{1} n_{2} & l_{1} m_{2}+l_{2} m_{1} & m_{1} n_{2}+m_{2} n_{1} & n_{1} l_{2}+n_{2} l_{1} \\
2 l_{2} l_{3} & 2 m_{2} m_{3} & 2 n_{2} n_{3} & l_{2} m_{3}+l_{3} m_{2} & m_{2} n_{3}+m_{3} n_{2} & n_{2} l_{3}+n_{3} l_{2} \\
2 l_{3} l_{1} & 2 m_{3} m_{1} & 2 n_{3} n_{1} & l_{3} m_{1}+l_{1} m_{3} & m_{3} n_{1}+m_{1} n_{3} & n_{3} l_{1}+n_{1} l_{3}
\end{array}\right\}
$$

In which, $l_{1}, l_{2}, l_{3}, m_{1}, m_{2}, m_{3}, n_{1}, n_{2}, n_{3}$ are corresponding direction cosines between the global coordinate system and local coordinate system.

\subsection{Constitutive relation}


The constitutive equation of a $k_{t h}$ orthotropic layer in principal axes coordinate is derived from Hooke's law for plane stress as

$$
\left\{\begin{array}{l}
\sigma_{1} \\
\sigma_{2} \\
\tau_{12} \\
\tau_{13} \\
\tau_{23}
\end{array}\right\}_{k}=\left[\begin{array}{ccccc}
Q_{11} & Q_{12} & Q_{16} & 0 & 0 \\
Q_{32} & Q_{22} & Q_{26} & 0 & 0 \\
Q_{61} & Q_{62} & Q_{66} & 0 & 0 \\
0 & 0 & 0 & Q_{44} & Q_{45} \\
0 & 0 & 0 & Q_{45} & Q_{44}
\end{array}\right]_{k}\left\{\begin{array}{l}
\varepsilon_{1} \\
\varepsilon_{2} \\
\gamma_{12} \\
\gamma_{13} \\
\gamma_{23}
\end{array}\right\}_{k}
$$

where material constants are given by

$$
Q_{11}=\frac{E_{1}}{1-v_{12} v_{21}} ; Q_{21}=\frac{v_{12} E_{2}}{1-v_{12} v_{21}} ; Q_{22}=\frac{E_{2}}{1-v_{12} v_{21}} ; Q_{66}=G_{12} ; Q_{55}=G_{13} ; Q_{44}=G_{23}
$$

where $E_{1}, E_{2}$ are the Young modulus in the 1 and 2 directions, respectively, and $G_{12}, G_{23}, G_{13}$ are the shear modulus in the 1-2, 2-3,3-1 planes, respectively, and $v_{i j}$ are Poisson's ratios.

And the constitutive equation of a $k_{t h}$ orthotropic layer in local coordinate as

$$
\left\{\begin{array}{l}
\sigma_{x x} \\
\sigma_{y y} \\
\tau_{x y} \\
\tau_{y z} \\
\tau_{x z}
\end{array}\right\}_{k}=\left[\begin{array}{ccccc}
Q_{11}^{\prime} & Q_{12}^{\prime} & Q_{16}^{\prime} & 0 & 0 \\
Q_{12}^{\prime} & Q_{22}^{\prime} & Q_{26}^{\prime} & 0 & 0 \\
Q_{16}^{\prime} & Q_{26}^{\prime} & Q_{66}^{\prime} & 0 & 0 \\
0 & 0 & 0 & Q_{44}^{\prime} & Q_{45}^{\prime} \\
0 & 0 & 0 & Q_{45}^{\prime} & Q_{55}^{\prime}
\end{array}\right]_{k}\left\{\begin{array}{l}
\varepsilon_{x x} \\
\varepsilon_{y y} \\
\gamma_{x y} \\
\gamma_{y z} \\
\gamma_{x z}
\end{array}\right\}_{k} \quad \text { or }\{\sigma\}_{k}=\left[Q^{\prime}\right]_{k}\{\varepsilon\}_{k}
$$

where

$$
\begin{aligned}
& Q_{11}^{\prime}=Q_{11} \cos ^{4} \alpha+2\left(Q_{12}+2 Q_{33} \cos ^{2} \alpha \sin ^{2} \alpha\right)+Q_{22} \sin ^{4} \alpha \\
& Q_{12}^{\prime}=\left(Q_{11}+Q_{22}-4 Q_{66}\right) \cos ^{2} \alpha \sin ^{2} \alpha+Q_{12}\left(\cos ^{4} \alpha+\sin ^{4} \alpha\right) \\
& Q_{22}^{\prime}=Q_{11} \cos ^{4} \alpha+2\left(Q_{12}+2 Q_{66}\right) \cos ^{2} \alpha \sin ^{2} \alpha+Q_{22} \cos ^{4} \alpha \\
& Q_{66}^{\prime}=\left(Q_{11}+Q_{22}-2 Q_{12}-2 Q_{66}\right) \cos ^{2} \alpha \sin ^{2} \alpha+Q_{66}\left(\cos ^{4} \alpha+\sin ^{4} \alpha\right) \\
& Q_{16}^{\prime}=\left(Q_{11}-Q_{22}-2 Q_{66}\right) \cos ^{3} \alpha \sin \alpha+\left(Q_{11}-Q_{22}-2 Q_{66}\right) \sin ^{3} \alpha \cos \alpha \\
& Q_{26}^{\prime}=\left(Q_{11}-Q_{22}-2 Q_{66}\right) \sin ^{3} \alpha \cos \alpha+\left(Q_{11}-Q_{22}-2 Q_{66}\right) \cos ^{3} \alpha \sin \alpha \\
& Q_{44}^{\prime}=Q_{44} \cos ^{2} \alpha+Q_{55} \sin ^{2} \alpha ; Q_{45}^{\prime}=\left(Q_{44}-Q_{55}\right) \cos \alpha \sin \alpha ; Q_{55}^{\prime}=Q_{44} \sin ^{2} \alpha+Q_{55} \cos ^{2} \alpha
\end{aligned}
$$

\subsection{Elastic stiffness matrix}

The element stiffness matrix is expressed as

$$
\left[K_{e}\right]=\int_{V_{e}}[B]^{T}\left[T_{\varepsilon}\right]^{T}\left[\mathrm{Q}^{\prime}\right]\left[T_{\varepsilon}\right][B] d x d y d z=\int_{V_{e}}[B]^{T}\left[T_{\varepsilon}\right]^{T}\left[\mathrm{Q}^{\prime}\right]\left[T_{\varepsilon}\right][B]|J| d \xi d \eta d \zeta
$$

And the element mass matrix can be written as

$$
\left[M_{e}\right]=\int_{V_{e}} \rho[\bar{N}]^{T}[\bar{N}] d x d y d z=\int_{V_{e}} \rho[\bar{N}]^{T}[\bar{N}]|J| d \xi d \eta d \zeta
$$


The integration in Eq. (20) and (21) are split through each layer by modifying the variable $\zeta$ to $\zeta_{k}$, in any $k_{t h}$ layer, $\zeta_{k}$ varies from -1 to +1 , facilitating the ease of Gauss numerical integration.

The change of variable from $\zeta$ to $\zeta_{k}$ is affected in the following manner:

$$
\begin{aligned}
& \zeta=-1+\frac{1}{h}\left[-h_{k}\left(1-\zeta_{k}\right)+2 \sum_{j=1}^{k} h_{j}\right] \\
& d \zeta=\left(\frac{h_{k}}{h}\right) d \zeta_{k}
\end{aligned}
$$

where $h_{k}$ is the thickness of the $k_{t h}$ layer. Applying the above transformation, the element stiffness matrix can be rewritten as

$$
\left[K_{e}\right]=\int_{-1}^{1} \int_{-1}^{1} \sum_{k=1}^{m} \int_{-1}^{1}[B]^{T}\left[T_{\varepsilon}\right]^{T}\left[Q^{\prime}\right]_{k}\left[T_{\varepsilon}\right][B]|J| \frac{h_{k}}{h} d \zeta_{k} d \xi d \eta
$$

And the element mass matrix can be rewritten as

$$
\left[M_{e}\right]=\int_{-1}^{1} \int_{-1}^{1} \sum_{k=1}^{m} \int_{-1}^{1} \rho^{k}[\bar{N}]^{T}[\bar{N}]|J| \frac{h_{k}}{h} d \zeta_{k} d \xi d \eta
$$

In which, $\mathrm{m}$ is number of layers, $\rho^{k}$ is specified weight and $[\bar{N}]=\left[\dot{N}_{1} \dot{N}_{2} \ldots \dot{N}_{i} \ldots \dot{N}_{8}\right]$

where $\quad \dot{N}_{i}=\left[\begin{array}{ccccc}N_{i} & 0 & 0 & \frac{\zeta h_{i}}{2} l_{1 i} N_{i} & \frac{\zeta h_{i}}{2} l_{2 i} N_{i} \\ 0 & N_{i} & 0 & \frac{\zeta h_{i}}{2} m_{1 i} N_{i} & \frac{\zeta h_{i}}{2} m_{2 i} N_{i} \\ 0 & 0 & N_{i} & \frac{\zeta h_{i}}{2} n_{1 i} N_{i} & \frac{\zeta h_{i}}{2} n_{2 i} N_{i}\end{array}\right]$.

By assembling, we obtain the stiffness matrix $[K]$ and mass matrix $[M]$ of the stiffened shell, thus the free vibration equation of the stiffened shell is expressed as follow

$$
[M]\{\ddot{\delta}\}+[K]\{\delta\}=0
$$

\section{NUMERICAL RESULTS AND DISCUSSIONS}

The finite element formulation described in the previous section has been used to investigate various numerical examples. Firstly, the accuracy of the present formulation is established by comparing the converged frequencies of specific problems available in the literature. Next numerical examples are carried out to study the effect of stiffener position, eccentricity of stiffeners on natural frequency of laminated stiffened composite cylindrical panels.

\subsection{Validation Example 1: Study of laminated composite beam using shell element}

In order to check the accuracy of using present degenerated shell element to model stiffener, let's consider the laminated composite cantilever beam. The dimensions of the beam are given: $\mathrm{L}=2 \mathrm{~m}, \mathrm{~b}=0.06 \mathrm{~m}, \mathrm{~h}=0.12 \mathrm{~m}$. Stacking sequence: $\left[0^{0} / 90^{\circ} / 0^{\circ} / 90^{0}\right]$. The material properties are given: $\mathrm{E}_{1}=25 \mathrm{E}_{2} \mathrm{~N} / \mathrm{m}^{2} ; \mathrm{G}_{12}=0.5 \mathrm{E}_{2} \mathrm{~N} / \mathrm{m}^{2} ; \mathrm{G}_{13}=\mathrm{G}_{12}=0.5 \mathrm{E}_{2} \mathrm{~N} / \mathrm{m}^{2} ; \mathrm{G}_{23}=0.2 \mathrm{E}_{2} \mathrm{~N} / \mathrm{m}^{2}$; 
$v=0.25 ; \rho=1500 \mathrm{~kg} / \mathrm{m}^{3}$. Concentrated force at free end of the beam: $P=10000 \mathrm{~N}$. The maximum deflection of the cantilever beam under concentrated force at the free end, and the free vibration frequency are presented in Table 1 . From the Table 1, it is seen that a slightly discrepancy between two results obtained by Ansys's SHELL99 element and present degenerated ShellDS8 element for modeling laminated composite beam.

Table 1. The maximum deflection and natural frequency of a rectangular laminated composite cantilever beam.

\begin{tabular}{|c|c|c|c|c|c|}
\hline \multirow{2}{*}{ Stiffener } & \multirow{2}{*}{ Type of element } & \multicolumn{3}{|c|}{ Frequency $(\mathrm{Hz})$} & \multirow{2}{*}{$\frac{\text { Max. Deflection }}{(\mathrm{m})}$} \\
\hline & & Mode 1 & Mode 2 & Mode 3 & \\
\hline \multirow{3}{*}{ : } & ANSYS - Shell99 (6 dofs) & 20.564 & 44.152 & 124.16 & 0.0244 \\
\hline & Matlab - ShellDS8 (6 dofs) & 20.635 & 44.171 & 124.44 & 0.0244 \\
\hline & Disperancy [\%] & 0.35 & 0.04 & 0.23 & 0.00 \\
\hline \multirow{3}{*}{ 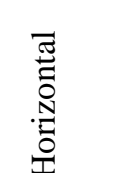 } & ANSYS - Shell99 (6 dofs) & 22.428 & 40.348 & 135.33 & 0.0291 \\
\hline & Matlab - ShellDS8 (6 dofs) & 22.467 & 40.464 & 134.84 & 0.0294 \\
\hline & Disperancy [\%] & 0.17 & 0.29 & -0.36 & 1.03 \\
\hline
\end{tabular}

\subsection{Validation Example 2: Study of laminated unstiffened double curved panel}

A four layered $[\theta /-\theta / \theta /-\theta]$ laminated doubly curved shell are analyzed by using degenerated shell element. The results are compared with those calculated by ANSYS software.

The properties of the doubly curved laminated composite shell as follows: $\mathrm{a}=1 \mathrm{~m} ; \mathrm{b}=1$ $\mathrm{m} ; \mathrm{R}_{1}=\mathrm{R}_{2}=5 \mathrm{a} ; \mathrm{a} / \mathrm{h}=50 ;$ All edge boundaries are clamped. $\mathrm{E}_{2}=1 \times 10^{9} \mathrm{~Pa} ; \mathrm{E}_{1}=25 \mathrm{E}_{2} ; \mathrm{G}_{12}=\mathrm{G}_{13}$ $=0.5 \mathrm{E}_{2} ; \mathrm{G}_{23}=0.2 \mathrm{E}_{2} ; \nu=0.25$ and $\rho=1500 \mathrm{~kg} / \mathrm{m}^{3}$.

The maximum deflection of the doubly curved shell under uniformly distributed transverse loading $q=1,000,000 \mathrm{~N} / \mathrm{m}^{2}$ and natural frequency with various angles of fiber orientation $\theta$ are presented in Table 2. It can be observed that the present results calculated by degenerated shell element are closer to the ANSYS's results. The difference between the frequencies obtained from the present finite element code and ANSY's software is less than $0.85 \%$. The maximum difference between the central deflections is $0.27 \%$.

Table 2. The maximum deflection and frequency of a doubly curved laminated composite shallow shell.

\begin{tabular}{|c|c|c|c|c|c|c|c|c|}
\hline \multirow{2}{*}{$\begin{array}{c}\text { Stacking } \\
\text { sequence }\end{array}$} & \multicolumn{9}{|c|}{ Frequency (Hz) } & \multicolumn{2}{c|}{ Max. Deflection } \\
\cline { 2 - 10 } & \multicolumn{2}{|c|}{ Mode 1 } & \multicolumn{2}{c|}{ Mode 2 } & \multicolumn{2}{c|}{ Mode 3 } & \multicolumn{2}{c|}{$(\mathrm{m})$} \\
\cline { 2 - 10 } & ANSYS & Present & ANSYS & Present & ANSYS & Present & ANSYS & Present \\
\hline $0 / 90 / 0 / 90$ & 135.12 & 135.34 & 174.23 & 174.69 & 175.00 & 175.46 & 0.0704 & 0.0702 \\
\hline $75 /-75 / 75 /-75$ & 134.79 & 134.96 & 147.31 & 147.91 & 176.44 & 177.96 & 0.0633 & 0.0634 \\
\hline $45 /-45 / 45 /-45$ & 129.13 & 129.48 & 164.99 & 165.56 & 165.50 & 166.05 & 0.0738 & 0.0736 \\
\hline $15 /-15 / 15 /-15$ & 134.69 & 134.96 & 147.28 & 147.91 & 176.40 & 177.96 & 0.0634 & 0.0634 \\
\hline
\end{tabular}




\subsection{Validation Example 3: Study of centrally cross-stiffened laminated composite doubly curved shell}

Consider a centrally cross-stiffened laminated composite doubly curved shell with laminated stiffener having stiffener laminae orientation vertical as shown in Figure 3.

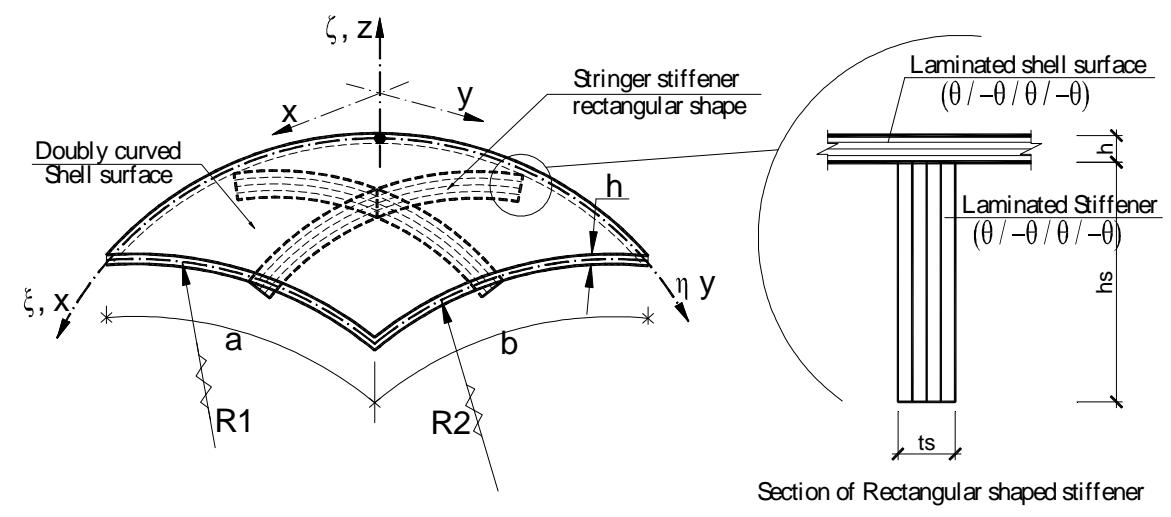

Figure 3. Geometry of doubly curved shell panel with stiffeners section is 'Rectangular' shape.

Dimensions of laminated doubly curved composite shell and stiffener are given: $\mathrm{a}=\mathrm{b}=0.5$ $\mathrm{m} ; \mathrm{a} / \mathrm{h}=50 ; \mathrm{t}_{\mathrm{s}}=0.01 \mathrm{~m} ; \mathrm{h}_{\mathrm{s}}=0.0150 \mathrm{~m}$; Stacking sequence of laminated shell and stiffeners is [0/90/0/90]. Composite material properties of shell and stiffener are as follows: $E_{2}=10 \mathrm{GPa} ; \mathrm{E}_{1}$ $=25 \mathrm{E}_{2} ; \mathrm{G}_{12}=0.5 \mathrm{E}_{2} ; \mathrm{G}_{23}=0.2 \mathrm{E}_{2} ; v_{12}=v_{23}=v_{13}=0.25$; All edge boundaries are clamped. Nondimensional natural frequencies of stiffened laminated composite shell are calculated as $\bar{\omega}=\omega \sqrt{\frac{\rho}{E_{2} h}}$. Table 3 depicts nondimensional fundamental natural frequencies of centrally crossstiffened laminated composite doubly curved shell with different stacking sequences and various shell radius-to-side ratio. The present results are compared with the results of Prusty [22] and the results calculated by ANSYS, and good agreement is observed.

Table 3. Nondimensional natural frequency of centrally cross-stiffened laminated composite doubly curved shell.

\begin{tabular}{|c|c|c|c|c|c|c|c|c|c|}
\hline \multirow{2}{*}{$\begin{array}{c}\text { Shell stacking } \\
\text { sequence }\end{array}$} & \multicolumn{3}{|c|}{$\mathrm{R} / \mathrm{a}=5$} & \multicolumn{3}{|c|}{$\mathrm{R} / \mathrm{a}=10$} & \multicolumn{3}{|c|}{$\mathrm{R} / \mathrm{a}=100$} \\
\hline & $\sum_{0}^{\vec{D}}$ & 永 & $\begin{array}{l}\overrightarrow{0} \\
\overrightarrow{0} \\
0 \\
0 \\
0\end{array}$ & 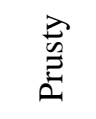 & 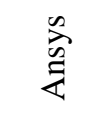 & $\begin{array}{l}\overrightarrow{0} \\
\stackrel{D}{0} \\
\stackrel{0}{0}\end{array}$ & $\underset{0}{2}$ & 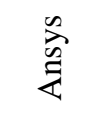 & $\begin{array}{l}\vec{\Xi} \\
\tilde{D} \\
\stackrel{0}{0}\end{array}$ \\
\hline 0/90/0/90 & 3.584 & 3.488 & 3.509 & 2.752 & 2.703 & 2.660 & 2.408 & 2.390 & 2.306 \\
\hline $45 /-45 / 45 /-45$ & 3.440 & 3.431 & 3.436 & 2.687 & 2.719 & 2.637 & 2.376 & 2.444 & 2.300 \\
\hline $75 /-75 / 75 /-75$ & 3.158 & 3.484 & 3.503 & 2.296 & 2.717 & 2.667 & 1.918 & 2.412 & 2.318 \\
\hline $15 /-15 / 15 /-15$ & - & 3.484 & 3.503 & - & 2.717 & 2.667 & - & 2.412 & 2.318 \\
\hline
\end{tabular}

\subsection{Parametric study}


A stiffened laminated composite cylindrical shell with all edges clamped is considered as Figure 4. The shell is cross-stiffened with the stiffeners placed at the center. The stiffeners are rectangular, the ply of stiffeners are placed in the horizontal position. Ply orientation of shell is taken as $\left[0^{0} / 90^{\circ} / 0^{0} / 90^{0}\right]$. The geometric dimensional are given: $\mathrm{a}=1 \mathrm{~m} ; \mathrm{b}=1 \mathrm{~m} ; \mathrm{h}=20 \times 10^{-3} \mathrm{~m}$; $\mathrm{t}_{\mathrm{s}}=30 \times 10^{-3} \mathrm{~m} ; \mathrm{h}_{\mathrm{s}}=50 \times 10^{-3} \mathrm{~m}$. Material properties are given: $\mathrm{E}_{1}=175.78 \times 10^{9} \mathrm{~Pa} ; \mathrm{E}_{2}=7.031 \times 10^{9}$ $\mathrm{Pa} ; \mathrm{G}_{12}=3.516 \times 10^{9} \mathrm{~Pa} ; \mathrm{G}_{23}=1.406 \times 10^{9} \mathrm{~Pa} ; \nu=0.25$ and $\rho=1500 \mathrm{~kg} / \mathrm{m}^{3}$.

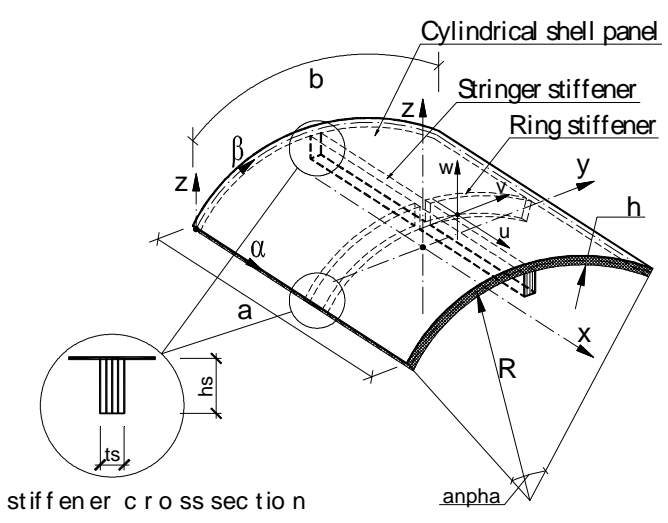

Figure 4. Centrally cross-stiffened laminated composite cylindrical shell.

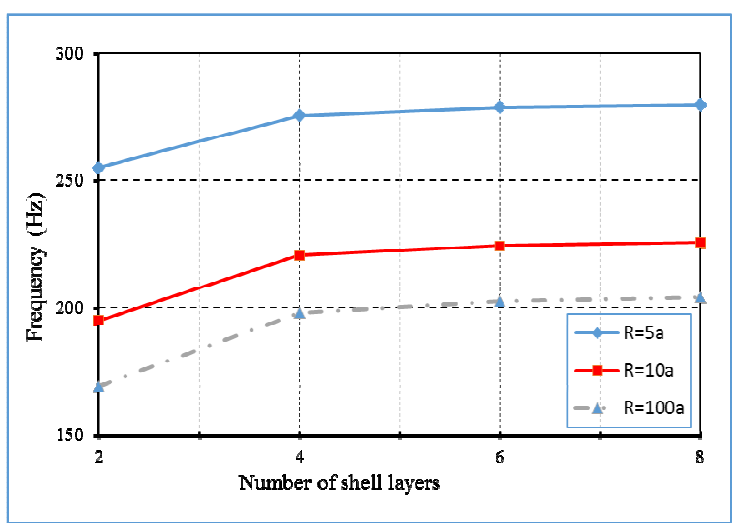

Figure 5. Variation of fundamental natural frequency versus number of shell layers with different curvature $\mathrm{R} / \mathrm{a}$ ratios.

\subsubsection{Effect of number of shell layers on the natural frequency of stiffened cylindrical shell}

Table 4 listed the three lowest natural frequencies of stiffened laminated cylindrical shell with varying curvature ratios $(\mathrm{R} / \mathrm{a})$. The stiffener ply orientation is taken as $\left[0^{\circ} / 90^{\circ} / 0^{\circ} / 90^{\circ}\right]$ and shell ply orientation is taken as $\left[0^{0} / 90^{0}\right]_{\mathrm{n}}$ with $\mathrm{n}=1 ; 2 ; 3 ; 4$ (constant shell thickness).

The variation of fundamental natural frequency versus number of shell layer with different curvature ratios is shown in Figure 5. From Table 4 and Figure 5, it can be seen that for all values of R/a, the natural frequencies increase with the increase of number of layers. The rate of increase of frequency slows down for higher values of shell layers.

Table 4. First three natural frequencies $[\mathrm{Hz}]$ of centrally cross-stiffened laminated composite cylindrical shell with various number of shell layers.

\begin{tabular}{|c|c|c|c|c|c|c|c|c|c|}
\hline \multirow{2}{*}{$\begin{array}{c}\text { Shell } \\
\text { stacking } \\
\text { sequence }\end{array}$} & \multicolumn{3}{|c|}{ R/a = } & \multicolumn{3}{c|}{ R/a =10 } & \multicolumn{3}{c|}{ R/a = 100 } \\
\cline { 2 - 9 } & 1 & 2 & 3 & 1 & 2 & 3 & 1 & 2 & 3 \\
\hline$\left[0^{0} / 90^{0}\right]$ & 255.2 & 281.2 & 360.3 & 195.1 & 226.2 & 326.7 & 169.1 & 203.3 & 309.1 \\
\hline$\left[0^{0} / 90^{0}\right]_{2}$ & 275.5 & 312.3 & 413.5 & 220.5 & 264.6 & 374.9 & 198.2 & 246.3 & 360.9 \\
\hline$\left[0^{0} / 90^{0}\right]_{3}$ & 278.7 & 317.8 & 420.3 & 224.4 & 271.1 & 382.7 & 202.6 & 253.3 & 369.1 \\
\hline$\left[0^{0} / 90^{0}\right]_{4}$ & 279.7 & 319.8 & 422.8 & 225.6 & 273.5 & 385.5 & 204.0 & 255.9 & 372.1 \\
\hline
\end{tabular}

\subsubsection{Effect of number of stiffener layers on the natural frequency of stiffened cylindrical shell}

The three lowest natural frequencies of stiffened laminated cylindrical shell with varying curvature ratios (R/a) are tabulated in Table 5. 
The shell ply orientation is taken as $\left[0^{\circ} / 90^{\circ} / 0^{\circ} / 90^{\circ}\right]$ and stiffener ply orientation is taken as $\left[0^{0} / 90^{\circ}\right]_{\mathrm{n}}$ with $\mathrm{n}=1 ; 2 ; 3 ; 4$ (constant stiffener width). Figure 6 illustrated the variation of fundamental natural frequency versus number of stiffener layers with different curvature ratios. From Table 5 and Figure 6, it can be observed that with the increase of the number of stiffener layers, the lowest three natural frequencies increase very slowly for all values of R/a, and practically it can be negligible.

Table 5. First three natural frequencies $[\mathrm{Hz}]$ of centrally cross-stiffened laminated composite cylindrical shell with various number of stiffener layers.

\begin{tabular}{|c|c|c|c|c|c|c|c|c|c|}
\hline \multirow{2}{*}{$\begin{array}{c}\text { Stiffener } \\
\text { stacking } \\
\text { sequence }\end{array}$} & \multicolumn{3}{|c|}{ R/a =5 } & \multicolumn{3}{c|}{ R/a $=10$} & \multicolumn{3}{c|}{ R/a $=100$} \\
\cline { 2 - 10 } & 1 & 2 & 3 & 1 & 2 & 3 & 1 & 2 & 3 \\
\hline$\left[0^{0} / 90^{0}\right]$ & 274.7 & 311.2 & 411.1 & 219.6 & 263.3 & 372.5 & 197.2 & 244.9 & 358.4 \\
\hline$\left[0^{\circ} / 90^{\circ}\right]_{2}$ & 275.5 & 312.3 & 413.5 & 220.5 & 264.6 & 374.9 & 198.2 & 246.3 & 360.9 \\
\hline$\left[0^{0} / 90^{0}\right]_{3}$ & 275.7 & 312.5 & 414.0 & 220.7 & 264.8 & 375.5 & 198.4 & 246.5 & 361.5 \\
\hline$\left[0^{0} / 90^{\circ}\right]_{4}$ & 275.8 & 312.6 & 414.3 & 220.8 & 264.9 & 375.8 & 198.6 & 246.6 & 361.7 \\
\hline
\end{tabular}

\subsubsection{Effect of number of the eccentricity of the stiffener}

For this investigation, the stiffener cross-sectional area is kept constant, and accordingly, the depth $\left(h_{s}\right)$ and the width $\left(t_{s}\right)$ of stiffeners are adjusted, thus the eccentricity $\left(h_{s} / t_{s}\right)$ of the stiffeners is varied. A four-layered cross-ply lamination sequences $\left[0^{\circ} / 90^{\circ} / 0^{\circ} / 90^{\circ}\right]$ in the shell and the stiffeners have been considered.

Table 6. First three natural frequencies of centrally cross-stiffened laminated composite cylindrical shell with different eccentricity of stiffener.

\begin{tabular}{|c|c|c|c|c|c|c|c|c|c|}
\hline \multirow{2}{*}{$\begin{array}{c}\text { Eccentricity } \\
\text { of stiffeners }\end{array}$} & \multicolumn{3}{|c|}{$\mathrm{R} / \mathrm{a}=5$} & \multicolumn{3}{c|}{$\mathrm{R} / \mathrm{a}=10$} & \multicolumn{3}{c|}{$\mathrm{R} / \mathrm{a}=100$} \\
\cline { 2 - 10 } & 1 & 2 & 3 & 1 & 2 & 3 & 1 & 2 & 3 \\
\hline & 260.9 & 298.9 & 373.2 & 202.9 & 249.6 & 332.2 & 178.9 & 230.4 & 317.0 \\
\hline $\mathrm{h}_{\mathrm{s}}=0.5 \mathrm{t}_{\mathrm{s}}$ & 268.2 & 305.1 & 393.4 & 211.8 & 256.5 & 354.3 & 188.7 & 237.7 & 339.8 \\
\hline $\mathrm{h}_{\mathrm{s}}=\mathrm{t}_{\mathrm{s}}$ & 268.2 & 27.7 & 262.7 & 370.5 & 196.2 & 244.2 & 356.3 \\
\hline $\mathrm{h}_{\mathrm{s}}=1.5 \mathrm{t}_{\mathrm{s}}$ & 273.9 & 310.6 & 409.2 & 218.6 & 262.7 & \\
\hline $\mathrm{h}_{\mathrm{s}}=2.0 \mathrm{t}_{\mathrm{s}}$ & 278.5 & 315.6 & 421.1 & 224.1 & 268.2 & 382.9 & 202.1 & 250.1 & 369.1 \\
\hline $\mathrm{h}_{\mathrm{s}}=2.5 \mathrm{t}_{\mathrm{s}}$ & 282.3 & 319.9 & 430.6 & 228.5 & 273.1 & 392.9 & 206.9 & 255.2 & 379.1 \\
\hline
\end{tabular}

Three lowest natural frequencies of stiffened laminated cylindrical shell with different eccentricity of stiffeners and various curvature ratios (R/a) are given in Table 6. Figure 7 shows the variation of fundamental natural frequencies of stiffened laminated cylindrical shell versus eccentricity of stiffeners. It can be seen that the natural frequencies of stiffened laminated cylindrical shell increases with increasing eccentricity of stiffeners for all values of R/a. 


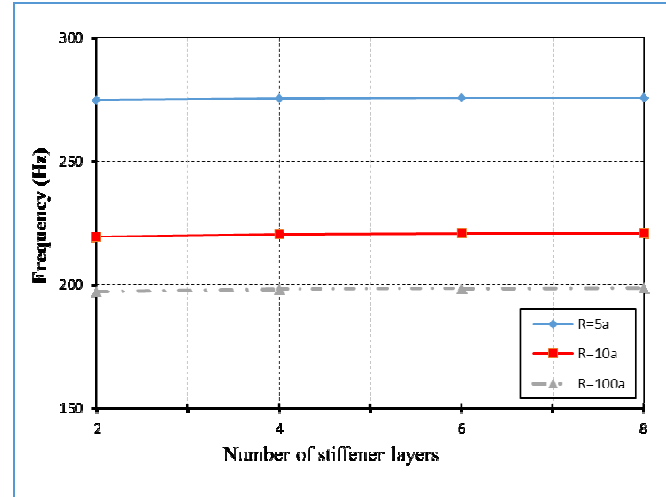

Figure 6. Variation of fundamental natural frequency versus number of stiffener layers with different curvature $\mathrm{R} / \mathrm{a}$ ratios.

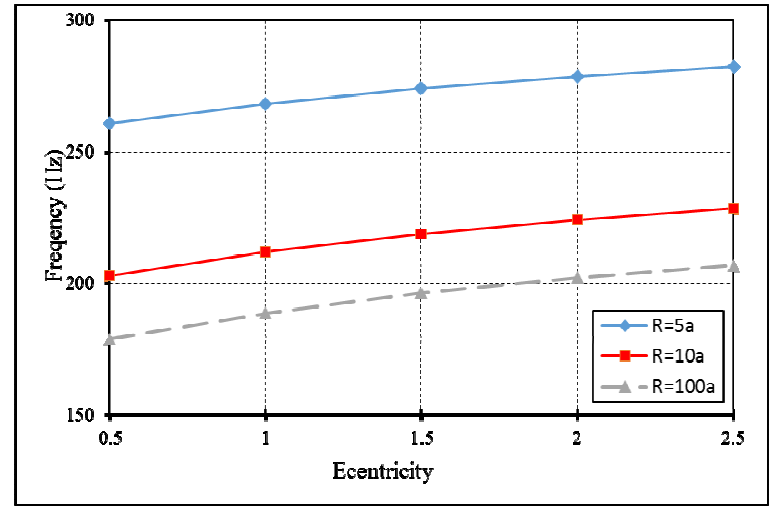

Figure 7. Variation of fundamental natural frequency vs. eccentricity of stiffener with different $\mathrm{R} / \mathrm{a}$ ratios.

\section{CONCLUSION}

This paper presents a formulation of the degenerated eight nodes shell finite element with six degrees of freedom per node. First order shear deformation theory has been adopted. A finite element program was developed using Matlab to analyze free vibration characteristic of laminated stiffened cylindrical composite shell. The accuracy and efficiency of the proposed shell finite element formulation are tested by three numerical examples, and results have a good agreement with the other reference solutions.

From the parametric study, it can be concluded that with constant thickness of the shell, the increasing the number of layers, the stiffened laminated shell stiffness can be increased (higher nature frequency). The influence of number of stiffener's layer can be negligible. Keeping the cross-sectional area of the stiffeners same for all the cases, it was found that depth of the stiffener is the guiding factor for the dynamic behavior of stiffened shell. As the depth increases, the strength of the structure also increases. With a fixed $\mathrm{R}$ value, the smaller is the value, the stronger is the structure.

The shell and stiffener finite elements presented in this paper can be applied to study the linear response and failure analysis of stiffened laminated composite shells.

\section{REFERENCES}

1. Leissa A. - Vibration of shell, Acoustical Society of America, 1993.

2. Soedel W. - Vibration of shells and plates. Taylor \& Francis e-Library, 2005.

3. Qatu M. S. - Vibration of laminated plates and shells, Elsevier Academic Press, 2004.

4. Szilard R. - Theories and Applications of plate analysis, John Wiley \& Sons, Inc., 2004.

5. Luan Y., Ohlrich M., Jacobsen F. - Smearing technique for vibration analysis of simply supported cross-stiffened and doubly curved thin rectangular shells, Journal of the Acoustical Society of America 129 (2011a) 707-716.

6. Luan Y., Ohlrich M., Jacobsen F. - Improvements of the smearing technique for crossstiffened thin rectangular plates. Journal of Sound and Vibration 330 (2011b) 4274-4286.

7. Mustafa B. A. J., Ali R. - Prediction of natural frequency of vibration of stiffened 
cylindrical shells and orthogonally stiffened curved panels. Journal of Sound and Vibration 113 (2) (1987) 317-327.

8. Bardell N. S., Mead D. J. - Free vibration of an orthogonally stiffened cylindrical shell. Part II: Discrete general stiffeners. Journal of Sound and Vibration 134 (1989) 55-72.

9. Goswami S., Mukhopadhyay M. - Finite Element Analysis of Laminated Composite Stiffened Shell. Journal of Reinforced Plastics and Composites 13 (1994) 574-616.

10. Goswami S., Mukhopadhyay M. - Finite Element Free Vibration Analysis of Laminated Composite Stiffened Shell. Journal of Composite Materials 29 (1995) 2388-2422.

11. Prusty B. G., Satsangi S. K. - Finite element transient dynamic analysis of laminated stiffened shells. Journal of Sound and Vibration 248(2) (2001a) 215-233.

12. Prusty B. G., Satsangi S.K. - Analysis of stiffened shell for ships and ocean structures by finite element method. Ocean Engineering 28 (2001b) 621-638.

13. Prusty B.G., Ray C., Satsangi S.K. - First ply failure analysis of stiffened panels - a finite element approach. Composite Structures 51 (2001c) 73-81.

14. Jiang J. and Olson M. D. - Vibration analysis of orthogonally stiffened cylindrical shells using super finite elements. Journal of Sound and Vibration 173 (1994) 73-83.

15. Nayak A. N., Bandyopadhyay - On the free vibration of stiffened shallow shells. Journal of Sound and Vibration 255(2) (2002) 357-382.

16. Samanta A., Mukhopadhyay M. - Free vibration analysis of stiffened shells by the finite element technique. European Journal of Mechanics A/Solids 23 (2004) 159-179.

17. Ahmad S., Irons B. M., Zienkiewicz O. C. - Analysis of thick and thin shell structures by curved finite element. International Journal for Numerical Methods in Engineering 2 (1970) 419-459.

18. Liao C. L., Cheng C. R. - Dynamic Stability of Stiffened Laminated Composite Plates and Shells Subjected To In-Plane Pulsating Forces. International Journal for Numerical Methods in Engineering 37 (1994) 4167 - 4183.

19. Patel S.N., Datta P.K., Sheikh A. H. - Buckling and dynamic instability analysis of stiffened shell panels. Thin-Walled Structures 44 (2006) 321-333.

\section{TÓM TẮT}

\section{PHÂN TÍCH DAO ĐỘNG RIÊNG CỦA PANEL TRỤ COMPOSITE LỚP CÓ GÂN GIA CƯỜNG BẰNG PHƯƠNG PHÁP PHẦN TỬ HỨU HẠN}

Trịnh Anh Tuấn ${ }^{1}$, Trần Hữu Quốc ${ }^{2}$, Trần Minh Tú2, *

${ }^{I}$ Công ty TNHH Tu vấn Thiết kế và Đào tạo HSE, 36B, ngõ 51, phố Đốc Ngũu, quận Ba Đình, Hà Nội, Việt Nam

${ }^{2}$ Truờng Đại học Xây dụng, 55 đường Giải Phóng, quận Hai Bà Trung, Hà Nội, Việt Nam

\section{"Email: tpnt2002@yahoo.com}

Bài báo trình bày phân tích dao động riêng của panel trụ composite lớp có gân gia cường. Phần tử vỏ suy biến đẳng tham số 8 nút được phát triển trên cơ sở phần tử khối và giả thiết 
Mindlin có kể đến biến dạng cắt ngang và mô men quán tính quay để mô hình hoá cả vỏ composite lớp và gân gia cường. Kết quả số được kiểm chứng qua so sánh với một số kết quả đã công bố. Ảnh hưởng của một số tham số hình học khác nhau của vỏ và gân đến đặc trưng dao động của vỏ có gân gia cường đã được thực hiện.

Tù khóa: vỏ composite lớp, vỏ có gân gia cường, tần số dao động riêng, phần tử hữu hạn, phần tử vỏ suy biến, phân tích tĩnh. 